\begin{tabular}{cccccc}
\multicolumn{5}{c}{ TABLE IV.-TOLUENE-DiPHENYL AT $25^{\circ}}$. & $\begin{array}{c}\text { Percentage } \\
\text { Per cent. diphenyl in mixture. }\end{array}$ \\
\hline Weight. & Volume. & Molecular. & $\eta$ (Expt.). & $\eta$ (Calculated). & $\begin{array}{c}\text { deviation from } \\
\text { mean value. }\end{array}$ \\
0.0 & 0.0 & 0.0 & 0.005520 & $\ldots$ & $\ldots$ \\
21.38 & 18.6 & 13.98 & 0.007335 & 0.0275 & -2.5 \\
32.02 & 28.2 & 21.97 & 0.008587 & 0.0281 & -0.4 \\
38.97 & 34.8 & 27.61 & 0.009627 & 0.0289 & +2.5
\end{tabular}

The constancy of $\eta_{2}$ is, in this case, not so good as in the previous systems, but still not unsatisfactory until we compare the value with that obtained in Table II. Just as for naphthalene above, a decided difference is evident in the two "calculated" values. It is of interest to note that the ratio $\left[\eta_{2}\right.$ on benzene basis $] /\left[\eta_{2}\right.$ on toluene basis] is practically identical for the two solutes, namely I.23 for naphthalene and I.22 for diphenyl.

The results of this paper also are consequently indecisive. All previous formulas are certainly useless. The cube-root equation gives good results for any single system, but the values for different systems containing the same solute are conflicting. No explanation of the results obtained can be ventured here, since it is obvious that more systems must be investigated before deductions of any value can be drawn.

NEW YORK CITY.

\title{
A STUDY OF THE ALLOTROPY OF CADMIUM.
}

BY FredERICK H. GetMan.

Received July 11, 1917.

Introduction.

To the interesting investigations of Ernst Cohen ${ }^{1}$ and his pupils we are indebted for practically all of our knowledge of the phenomenon of allotropy among the metals. By means of the pycnometer, the dilatometer and the potentiometer, he has shown that tin, bismuth, cadmium, copper, zinc, antimony, lead, sodium and potassium exist in different allotropic modifications, each of which possesses a more or less definite range of stability.

In studying the electromotive behavior of cadmium, Cohen ${ }^{2}$ made use of a cell set up according to the following scheme, the direction of the current outside of the cell being shown by the arrow:

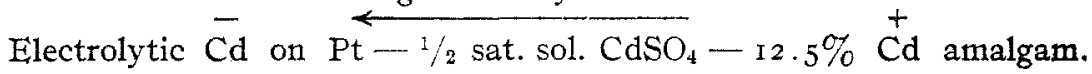
Similar cells have also been investigated by Jaeger, ${ }^{3}$ Bijl, ${ }^{4}$ and Hulett."

1 Verslag Akad. Wetenschappen, 16, 485, 565, 628, 632, 807 (1913-14); 17, 54, 59. 60, 122, 200 (Igr4); $Z$. phys. Chem., 85, 4 19 (1913); 87, 409, 419, 426, 431 (1914).

2 Trans. Faraday Soc., I0, 216 (I9I5).

${ }^{3}$ Ann. Physik, [3] 65, 106 (1898).

'Z. phys. Chem., 4I, 64I (1902).

-Trans. Am. Electrochem. Soc., 7, 353 (1905). 
All of these investigators found the e. $\mathrm{m}$. $\mathrm{f}$. of freshly prepared cells to be 0.0505 volt at $25^{\circ}$, the order of reproducibility being about 0.5 millivolt. Out of a large number of such cells, Cohen found that approximately $30 \%$ were stable, while the e. $\mathrm{m}$. f. of the remaining cells slowly decreased over a period of several weeks and finally became constant. The equilibrium value of the e. $\mathrm{m}$. $\mathrm{f}$. of some of these cells was found to be 0.047 volt at $25^{\circ}$, while for others it was found to be 0.048 volt. Combining these facts together with the data obtained from his dilatometric studies on cadmium, Cohen concluded that the three different values of the e. $\mathrm{m}$. $\mathrm{f}$. of his cells might be ascribed to the presence on the negative electrode of three different modifications of cadmium, which he designated as $\mathrm{Cd}_{\boldsymbol{\alpha}}, \mathrm{Cd}_{\beta}$, and $\mathrm{Cd}_{\gamma}$. The negative electrodes of cells, of which the e. m. f. was 0.050 volt at $25^{\circ}$, were assumed to consist of $\mathrm{Cd}_{\gamma}$, while the negative electrodes of cells giving 0.048 and 0.047 volt at $25^{\circ}$ were assumed to consist of $\mathrm{Cd}_{\beta}$ and $\mathrm{Cd}_{\alpha}$, respectively.

In his investigations on stannic salts, Cohen found, contrary to expectation, that when solutions of these salts were electrolyzed at temperatures below $18^{\circ}$ (the temperature at which grey tin undergoes transformation into white tin), there was deposited at the cathode not grey tin, but the modification which is metastable at those temperatures. By analogy he assumed that in all probability the cadmium which was deposited electrolytically on the negative electrodes of his cells was also metastable at room temperatures and consequently he ascribed the highest value of the e. m. f., viz., 0.050 volt, to the presence of $\mathrm{Cd}_{\gamma}$.

Cohen tested the validity of his conclusions as to the existence of $\mathrm{Cd}_{\alpha}$, $\mathrm{Cd}_{\beta}$, and $\mathrm{Cd}_{\gamma}$, by measuring the e. m. f. of cells assumed to contain these different modifications at several different temperatures. The resulting change in e. m. f. was such as apparently to confirm his hypothesis.

Object of Investigation.--In the course of some experimental work on the temperature coefficient of cells similar to those studied by Cohen, the author was surprised to find that this coefficient undergoes a reversal of sign in the vicinity of $40^{\circ}$. The possible bearing of this phenomenon on the allotropy of cadmium made it seem worth while to undertake a systematic investigation of these cells at a series of temperatures both above and below $40^{\circ}$. The present paper contains a brief summary of the results obtained.

\section{Materials and Apparatus.}

All of the materials used in preparing the cells were purified with extreme care. Two different samples of cadmium were used in the preparation of the amalgams. While these samples were guaranteed to contain only traces of impurities, each was subjected to vacuum distillation before use. The mercury employed was redistilled by the familiar method of Hulett. ${ }^{1}$

2 Phys. Rev., 32, 257 (191 I). 
Several different samples of high grade cadmium sulfate were obtained and recrystallized in vacuo, care being taken to so regulate the temperature as to secure crystals of the hydrate represented by the formula $\mathrm{CdSO}_{4}, 8 / 3 \mathrm{H}_{2} \mathrm{O}$. Both solutions and amalgams were prepared by direct weighing.

All measurements of e. m. f. were made by means of a potentiometer, accurate to within 0.02 millivolt, and a sensitive galvanometer. A Weston cell, recently certified by the Bureau of Standards to give I.0I85 I volts at $23.8^{\circ}$, was used as a standard of comparison.

Two different electrically heated thermostats were employed. One thermostat was constantly maintained at $20^{\circ} \pm 0.0 \mathrm{I}^{\circ}$, while the temperature of the other was varied from $10^{\circ}$ to $80^{\circ}$ with an accuracy of control not exceeding $0.1^{\circ}$. The lowest temperatures recorded were obtained by the use of finely crushed ice. All of the thermometers used were compared with a standard thermometer which had been calibrated at the Physikalische Reichsanstalt.

Preparation of the Cells.--It has been shown by Bijl ${ }^{1}$ that all amalgams containing between 5 and $14 \%$ of cadmium have the same e. m. f. when measured against any constant electrode at room temperature. An $8 \%$ amalgam was selected for the positive electrode in preference to the I $2.5 \%$ amalgam used by Cohen in his experiments at $25^{\circ}$, because at $0^{\circ}$, as Bijl has shown, the $12.5 \%$ amalgam forms a monophase system and such a system must not be used for the positive electrode of a cell. The $8 \%$ amalgam, prepared by direct weighing, was introduced into one arm of an $\mathrm{H}$-shaped cell until a layer about $\mathrm{I} \mathrm{cm}$. in depth was formed. Electrical connection with the amalgam was established in the usual manner by means of a platinum wire sealed into a glass tube containing mercury.

The $\mathrm{H}$-shaped vessel was then filled slightly above the horizontal portion with a solution of cadmium sulfate containing $2 \mathrm{I} .68 \mathrm{~g}$. of $\mathrm{CdSO}_{4} .8 / 3 \mathrm{H}_{2} \mathrm{O}$ per $100 \mathrm{~g}$. of solution at $20^{\circ}$, this concentration corresponding to halfsaturation. It is not essential that the concentration be adjusted with great precision, because it has been shown by Hulett ${ }^{2}$ and others that the e. $\mathrm{m}$. f. of this cell is independent of the concentration of the electrolyte and also of the presence of solid salt.

The negative electrode consisted of a flattened platinum spiral sealed into a glass tube and covered with an electrolytic deposit of cadmium. The deposition of cadmium was effected in a small cell containing a halfsaturated solution of cadmium sulfate to which a few drops of concentrated sulfuric acid had been added. A I \% cadmium amalgam served as the anode. On passing a current of I milliampere through this cell

I Loc. cit.

2 Trans. Am. Eleclrochem. Soc., 7, 353 (1905). 
for several hours a closely adherent deposit of cadmium was secured on the platinum spiral. A current of I milliampere will deposit approximately $2 \mathrm{mg}$. of cadmium per hour. When a sufficient deposit of cadmium was obtained, the spiral was removed and inserted as the negative electrode in the experimental cell. A large number of these cells were prepared which were identical in all respects except that the mass of cadmium deposited on the platinum spirals was intentionally varied. The thickness of the deposit of cadmium on the platinum spirals was sufficient to insure each electrode functioning as a cadmium electrode. A surprisingly thin layer of metal is required to achieve this result, it having been shown by Oberbeck ${ }^{1}$ that a layer of not more than $2 \times{ }_{10}^{-6} \mathrm{~mm}$. is sufficient to impart to a platinum surface the potential of the deposited metal.

Experimental Data.-The cells were placed in the thermostat immediately after preparation and maintained at $20^{\circ}$ for at least half an hour before any measurements were undertaken. Only a small proportion of all of the cells investigated were found to maintain their high initial e. m. f., in fact only $10 \%$ of the cells were found to give the constant voltage attributed by Cohen to $\mathrm{Cd}_{\gamma}$. While all of the cells gave approximately the same initial e. m. f., this was found to decrease slowly for $90 \%$ of the cells. Of this number, $20 \%$ finally became constant at an e. $\mathrm{m}$. f. corresponding to Cohen's $\alpha$-cells and $70 \%$ at an e. m. f. corresponding to his $\beta$-cells.

The average values of the e. $\mathrm{m}$. f. of these three different types of cells at temperatures ranging from $0^{\circ}$ to $40^{\circ}$ are given in the following tables. The corrected temperatures are given in the first column of the tables, while in the second column are given the values of the e. m. f. calculated by means of interpolation formulas derived by the method of least squares from the experimental data for six typical cells. The interpolation formula used in calculating the values of the e. m. f. of the $\gamma$-cells was derived by Cohen. ${ }^{2}$ The third column of the tablés gives the average observed values of the e. $\mathrm{m}$. $\mathrm{f}$. while the last column gives the differences between the observed and calculated values of the e. $\mathrm{m}$. $\mathrm{f}$.

TABLE I.

Average Data for $\gamma$-Cells.

$\begin{array}{rrrr}\text { Interpolation Formula: } & \mathrm{E}=0.05047-0.0002437 & (t-25) . \\ \text { Temp. } & \text { E (calc.). } & \mathrm{E} \text { (obs.). } & \Delta^{\prime} . \\ 2.0^{\circ} & 0.05608 & 0.05535 & -0.00073 \\ 19.7^{\circ} & 0.05176 & 0.05156 & -0.00020 \\ 25.0^{\circ} & 0.05047 & 0.05063 & +0.00016 \\ 30.0^{\circ} & 0.04925 & 0.04950 & +0.00025 \\ 35.0^{\circ} & 0.04803 & 0.04804 & +0.00001 \\ 40.0^{\circ} & 0.0468 \mathrm{I} & 0.04735 & +0.00054\end{array}$

${ }^{1}$ Ann. Phys., [3] 3I, 337 (1881).

${ }^{2}$ Trans. Faraday Soc., Io, 2 I6 (I915). 
TABLE II.

Average Data for $\beta$-Cells.

Interpolation Formula: $\mathrm{E}_{i}=0.04862-0.000201(t-25)$.

$\begin{array}{cccc}\text { Temp. } & \text { E (calc.) } & \text { E (obs.). } & \Delta_{1 .} \\ 0.4^{\circ} & 0.05356 & 0.05349 & -0.00007 \\ 11.36^{\circ} & 0.05136 & 0.05138 & +0.00002 \\ 19.70^{\circ} & 0.04973 & 0.04967 & -0.00006 \\ 25.57^{\circ} & 0.04851 & 0.04854 & +0.00003 \\ 30.51^{\circ} & 0.04751 & 0.04753 & +0.00002 \\ 35.60^{\circ} & 0.04649 & 0.04657 & +0.00008\end{array}$

TABLE IIT.

Average Data for $\alpha$-Cells.

Interpolation Formula: $\mathrm{E}=0.0474^{2}-0.000200(t-25)$.

$\begin{array}{cccc}\text { Temp. } & E \text { (calc.) } & \text { E (obs.). } & \Delta^{\prime} . \\ 1.0^{\circ} & 0.05222 & 0.05225 & +0.00003 \\ 10.0^{\circ} & 0.05042 & 0.05042 & 0.00000 \\ 15.0^{\circ} & 0.04942 & 0.04948 & +0.00006 \\ 19.7^{\circ} & 0.04868 & 0.04828 & -0.00040 \\ 30.0^{\circ} & 0.04642 & 0.04614 & -0.00028 \\ 40.0^{\circ} & 0.04442 & 0.04410 & -0.00032\end{array}$

It will be observed that the agreement between the observed and calculated values of the e. m. $f$. is, in nearly every case, well within the limit of reproducibility of the cells. These results justify the conclusion that the e. m. $f$. of cells of this type is a linear function of the temperature.

On raising the temperature of the cells above $40^{\circ}$, the temperature coefficients were found to undergo a reversal of sign. The values of the e. $\mathrm{m}$. $\mathrm{f}$. given by the different cells when maintained for a short time at a temperature above $40^{\circ}$ were found to be quite divergent. On prolonged standing at this temperature, however, the divergence in e. m. $f$. was found to disappear and final equilibrium values agreeing within the limits of experimental error were obtained.

It was found that stabilization between $40^{\circ}$ and $80^{\circ}$ could be brought about more quickly by maintaining the cells at a temperature of $95^{\circ}$ for several days. From the data obtained with five cells which had been stabilized in this manner an interpolation formula was derived by the method of least squares. On applying this formula to the data obtained with other cells, satisfactory agreement between the observed and calculated values of $e$. $m$. f. was secured.

The stabilization of a cell above $40^{\circ}$ together with its previous and subsequent behavior, may be illustrated by giving the complete experimental data for a single typical cell. The following table gives the complete data for cell F-8 from May 5, I9I7, the date of its preparation, to June 12, I9I7, when measurements were discontinued: 
TABIE IV.

Cell F-8; Mass of Cd Deposited on Negative Electrode, $8.4 \mathrm{Mg}$.

\begin{tabular}{|c|c|c|c|}
\hline Temp. & E (calc.). & E (obs.). & $\Delta$. \\
\hline $19.7^{\circ}$ & $0.05176^{1}$ & $0.05063^{2}$ & -0.00113 \\
\hline $19.7^{\circ}$ & $0.04973^{3}$ & $0.0497 I^{4}$ & -0.00002 \\
\hline $0.4^{\circ}$ & $0.05356^{3}$ & $0.0535^{8}$ & +0.00002 \\
\hline II $.36^{\circ}$ & $0.05136^{3}$ & 0.05129 & -0.00007 \\
\hline $19.70^{\circ}$ & $0.04973^{3}$ & 0.04966 & -0.00007 \\
\hline $25.13^{\circ}$ & $0.04859^{3}$ & 0.04866 & +0.00007 \\
\hline $30.51^{\circ}$ & $0.0475 x^{3}$ & 0.04730 & -0.00021 \\
\hline $35.60^{\circ}$ & $0.04649^{3}$ & 0.04653 & to.00004 \\
\hline $40.24^{\circ}$ & $0.04539^{5}$ & 0.04666 & to.00127 \\
\hline $44.97^{\circ}$ & $0.04619^{5}$ & 0.04741 & +0.00122 \\
\hline $50.51^{\circ}$ & $0.04714^{5}$ & 0.04827 & +0.00113 \\
\hline $55.51^{\circ}$ & $0.04799^{B}$ & 0.04884 & to.00085 \\
\hline $60.74^{\circ}$ & $0.04888^{5}$ & 0.04972 & to.00084 \\
\hline $65.52^{\circ}$ & $0.04969^{6}$ & 0.05054 & to.00085 \\
\hline $7 \mathrm{I} \cdot \mathrm{II}^{\circ}$ & $0.05064^{5}$ & 0.05147 & +0.00083 \\
\hline $69.87^{\circ}$ & $0.05041^{5}$ & $0.05053^{6}$ & to.00012 \\
\hline $65.25^{\circ}$ & $0.04964^{5}$ & $0.0496 I^{6}$ & -0.00003 \\
\hline $60.66^{\circ}$ & $0.04886^{5}$ & $0.04895^{6}$ & +0.00009 \\
\hline $54.39^{\circ}$ & $0.04779^{5}$ & $0.04769^{6}$ & $\rightarrow 0.00010$ \\
\hline $50.09^{\circ}$ & $0.04707^{5}$ & $0.04685^{\circ}$ & -0.00022 \\
\hline $35.71^{\circ}$ & $0.045^{2} 8^{7}$ & $0.0448 \mathrm{I}^{6}$ & -0.00047 \\
\hline $31.08^{\circ}$ & $0.04620^{7}$ & $0.04575^{8}$ & -0.00045 \\
\hline $21.00^{\circ}$ & $0.04822^{7}$ & $0.04764^{8}$ & -0.00058 \\
\hline
\end{tabular}

It will be observed that the initial e. $m$. $f$. of the freshly prepared cell was slightly less than that calculated for a $\gamma$-cell and slightly greater than that corresponding to a $\beta$-cell. After standing at $19.7^{\circ}$ for three days, the cell apparently had become stabilized as a $\beta$-cell. The agreement between the observed and calculated values up to $40^{\circ}$ is all that could be desired. When the cell was heated above $40^{\circ}$, the observed values of the e. m. f. were greater than those calculated by means of the interpolation formula. It is interesting to note that while the observed values of the e. m. f. for temperatures between $40^{\circ}$ and $70^{\circ}$ were all greater than the calculated values, yet the differences between these values diminished as the temperature was raised. After heating the cell for two days and then allowing to cool, the agreement between the observed and calculated values of the e. m. f. was entirely satisfactory. When the cell was cooled below $40^{\circ}$ it was found that it no longer functioned as a $\beta$-cell,

1 Calculated for $\gamma$-cell.

2 E. m. f. of freshly prepared cell.

8 Calculated for $\beta$-cell.

4. E. I. after standing 3 days at $19.7^{\circ}$.

- Calculated by formula, $\mathrm{E}=0.04280+0.000170(t-25)$.

- After heating for 48 hours at $95^{\circ}$.

7 Calculated for $\alpha$-cell. 
but that it had undergone transformation into an $\alpha$-cell. The behavior of each of the other cells was found to be similar to that of cell F-8.

\section{Discussion of Results.}

The discontinuity in the curves expressing the e. m. f. of these cells as a function of temperature must be caused by the occurrence of an abrupt physical change in the electrolyte, in the amalgam, or in the cadmium deposit. The fact that the electrolytic solution is only half saturated precludes the possibility of the discontinuity being due to changes in the degree of hydration of the electrolyte. Should the degree of hydration change in the solution it would exert no influence on the e. $m$. f. of the cell since the investigations of Hulett and others have shown that the e. m. f. of cells of this type is independent of the concentration of the electrolyte. Furthermore, a saturated solution of $\mathrm{CdSO}_{4} .8 / 3 \mathrm{H}_{2} \mathrm{O}$ has been shown by Mylius and Funk, ${ }^{1}$ and also by Kohnstamm and Cohen, ${ }^{2}$ to be stable between $-18^{\circ}$ and $74.5^{\circ}$. That the discontinuity cannot be ascribed to any change in the amalgam has been proven by the investigations of $\mathrm{Bij} 1,{ }^{3}$ in which the e. m. $\mathrm{f}$. of a cell formed by connecting an $8 \%$ cadmium amalgam with a standard electrode was found to decrease regularly as the temperature was raised from $25^{\circ}$ to $75^{\circ}$. Consequently we are forced to attribute the discontinuity to the occurrence of some abrupt change in the cadmium deposit constituting the negative electrode of the cell. The simplest and perhaps the most rational explanation is, that the cadmium which forms the negative electrode of the cell undergoes a change from one allotropic modification to another at a temperature in the neighborhood of $40^{\circ}$. The precise value of this transition temperature may be easily calculated by equating the interpolation formula for cells in which $\mathrm{Cd}_{\alpha}$ forms the negative electrode to the corresponding formula for cells stabilized above the transition temperature, and solving the resulting equation for $i$. Thus:

$$
0.04742-0.000200(t-25)=0.04280+0.000170(t-25) \text {, }
$$

from which we find that $t=37.49^{\circ}$.

This value of the transition temperature does not agree with that found by Cohen with the dilatometer. In his dilatometric experiments, he found that the transition temperature of cadmium varied from $6 \mathrm{I} \cdot 3^{\circ}$ to $69 \cdot 3^{\circ}$, and that at one and the same temperature both expansion and contraction occurred.

From these facts Cohen assumed the simultaneous existence of more than two allotropic modifications of cadmium.

Recognizing the difficulty, if not the impossibility, of determining the true transition points of the pure modifications of cadmium by using

${ }^{1}$ Ber., 30, 824 (1897).

Ann. Phys., [3] 65, 344 (1898).

Loc cit. 
samples of the metal containing more than a single allotrope, he prepared I $70 \mathrm{~g}$. of electrolytic cadmium which his previous investigations had led him to believe to be physically and chemically homogeneous. When this material was studied in the dilatometer no change was found to occur at $50^{\circ}, 80^{\circ}$, or $100^{\circ}$. On removing the electrolytic cadmium from the dilatometer and freeing it from adhering paraffin oil it was subjected to treatment with a solution of cadmium sulfate for 12 hours at $100^{\circ}$ and then for 48 hours at $50^{\circ}$. After this treatment it was replaced in the dilatometer and a change in the direction of motion of the oil meniscus was observed at a constant temperature of $70.5^{\circ}$. These experiments, Cohen thinks, establish beyond doubt the simultaneous existence of more than two modifications of cadmium.

It must be borne in mind, however, that in each of these dilatometric measurements never less than $300 \mathrm{~g}$. of cadmium were used, and it is a well-established fact that when so large a mass of metal undergoes molecular transformation the true transition temperature may be far removed from that at which the transformation actually takes place. On the other hand, the method which we have used to determine the transition temperature is not open to this objection. Only a very small mass of cadmium is involved and consequently only a short interval of time is required for complete transformation of one allotrope into the other when once the transition temperature has been passed. The influence of mass on the velocity of allotropic transformation has been observed repeatedly during the present investigation. The time required for stabilization of the different cells was found to be roughly proportional to the mass of the cadmium deposits.

The data of Table IV, as well as the data of other similar tables not included in this paper, seems to justify the conclusion that the form of cadmium which is stable below $37.5^{\circ}$ is that which results from prolonged immersion of the electrolytically deposited metal in a solution of cadmium sulfate at room temperature, and corresponds to that modification of the metal designated by Cohen as $\mathrm{Cd}_{\alpha}$.

On the other hand, the form of cadmium which is stable above $37.5^{\circ}$ (within the range of temperature covered by these experiments) is that which results from prolonged heating of the electrolytically deposited metal in a solution of cadmium sulfate in the neighborhood of $90^{\circ}$. This modification of cadmium we shall designate as $\mathrm{Cd}_{\beta}$. It is important to observe that the modification here designated as $\mathrm{Cd}_{\beta}$ is not identical with the $\mathrm{Cd}_{\beta}$ of Cohen.

As has been mentioned, Cohen assumed the presence of $\mathrm{Cd}_{\beta}$ in all of his cells which gave a constant e. m. f. of 0.048 volt at $25^{\circ}$. In order to confirm the existence of a definite transition temperature in the vicinity of $60^{\circ}$, as his dilatometric experiments had indicated, Cohen carried out 
several experiments with cells containing $\mathrm{Cd}_{\alpha}$ and $\mathrm{Cd}_{\beta}$ above and below this temperature.

At temperatures above $60^{\circ}$, the e. m. f. of cells containing $\mathrm{Cd}_{\alpha}$ should be higher than that of cells containing $\mathrm{Cd}_{\beta}$, while at temperatures below $60^{\circ}$, the reverse should occur. He selected two cells, one of which (No. 7) gave an e. m. f. of 0.047 volt at $25^{\circ}$, and the other (No. 22) which gave an e. m. f. of 0.048 volt at $25^{\circ}$. These two cells were connected by a siphon containing a solution of cadmium sulfate of the same concentration as that present in the cells. The e. $m$. f. of the electrolytically deposited cadmium in the cells was measured successively against one of the two amalgam electrodes, a common electrode being chosen in order to eliminate possible errors due to slight differences in composition of the two amalgams. The results obtained are given in Table V, together with the results of two other experiments, one by Cohen with cells Nos. 8 and 4 and the other by the author with cells B-I and A-I.

\begin{tabular}{rccc}
\multicolumn{3}{c}{ TABLE V. } \\
Cell. & $\overbrace{25^{\circ} .}$ & $64.5^{\circ}$. & $25^{\circ}$. \\
7 & 0.04741 & 0.04029 & $0.0474 \mathrm{I}$ \\
22 & 0.04815 & 0.03979 & 0.04806 \\
8 & 0.04757 & 0.04737 & 0.04776 \\
4 & 0.04839 & 0.04633 & 0.04789 \\
B-I & 0.04729 & 0.04734 & 0.04772 \\
A-I & 0.04823 & 0.04652 & 0.04822
\end{tabular}

It will be observed that at $64.5^{\circ}$, the e. m. f. of cells 7,8 and B-I was greater than that of cells 22,4 and A-I, whereas at $25^{\circ}$, the e. m. f. of the latter group of cells was greater than that of the former. From this inversion of poles Cohen concluded that an actual transformation of $\mathrm{Cd}_{\alpha}$ into $\mathrm{Cd}_{\beta}$ occurs in the neighborhood of $60^{\circ}$.

The author's data for cells A-I and B-I appears to confirm this conclusion, but when the e. m. f. of these cells was determined at close intervals of temperature from $0^{\circ}$ to $70^{\circ}$ no evidence of a transition temperature in the vicinity of $60^{\circ}$ was obtained. On the other hand, distinct discontinuities in the e. m. f.-temperature curves were obtained at $39^{\circ}$ with A-I, and at $36.8^{\circ}$ with B-I. Since the agreement between Cohen's cells and the author's at $25^{\circ}$ and $64.5^{\circ}$ is satisfactory, it is highly probable that equally close agreement would have been obtained at other temperatures and that had Cohen measured his cells over a wider range of temperature and plotted the values of e. $\mathrm{m}$. $\mathrm{f}$. against the temperatures he would have obtained no evidence of a transition point at $60^{\circ}$.

The molecular rearrangement which takes place at a transition point must cause a marked diminution in the internal frictional resistance of the substance undergoing change. In describing his dilatometric 
experiments, Cohen frequently refers to the fact that cadmium can be "brought into motion" most quickly by heating it for several hours in a solution of cadmium sulfate in the neighborhood of $40^{\circ}$. The cause of this phenomenon is probably to be found in the greater molecular freedom which occurs at $37.5^{\circ}$, the temperature at which reversible transformation between $\mathrm{Cd}_{\alpha}$ and $\mathrm{Cd}_{\beta}$ has been shown to take place.

As has been mentioned, Cohen attributed the high initial e. m. f. of his cells to the presence of a third modification of cadmium which he designated as $\mathrm{Cd}_{\gamma}$. On the assumption that the negative electrodes of all of his freshly prepared cells consisted of $\mathrm{Cd}_{\gamma}$ and that this modification undergoes a gradual transformation into $\mathrm{Cd}_{\alpha}$ when immersed in a solution of cadmium sulfate, Cohen computed the temperature at which one form changes into the other. By equating the interpolation formulas for his so-called $\alpha$ - and $\gamma$-cells, as follows:

$$
0.05047-0.0002437(t-25)=0.04742-0.000200(t-25),
$$

he found that $t=94.8^{\circ}$.

The results of the present investigation, however, seem to render the existence of more than two allotropic modifications of cadmium between $0^{\circ}$ and $100^{\circ}$ extremely doubtful.

\section{Summary.}

(I) The e. m. f. of cells prepared according to the scheme

$$
\overline{\mathrm{Cd}}-1 / 2 \text { sat. sol. } \mathrm{CdSO}_{4}-8 \% \stackrel{+}{\mathrm{Cd}} \text { amalgam, }
$$

has been measured at intervals of $10^{\circ}$, or less, from $0^{\circ}$ to $70^{\circ}$. The initial value of the.e. m. f. at $20^{\circ}$ was found to diminish with time and finally to become constant.

(2) On heating a cell thus stabilized the e. m. f. was found to be a decreasing linear function of the temperature for all temperatures below $40^{\circ}$.

(3) On maintaining a cell at a temperature in the neighborhood of $90^{\circ}$ for several days, complete stabilization was secured. The e. m. f. of cells stabilized in this manner was found to be an increasing linear function of the temperature for all temperatures above $40^{\circ}$. The rate of increase of e. m. f. above $40^{\circ}$ was found to be slightly less than the rate of decrease of e. m. f. below $40^{\circ}$.

(4) By means of interpolation formulas derived from the experimental data, the value of the temperature at which the e. m. f. reaches its minimum value has been calculated and found to be $37.5^{\circ}$.

(5) This temperature may be regarded as a close approximation to the transition point in the system, $\mathrm{Cd}_{\alpha} \rightleftarrows \mathrm{Cd}_{\beta}$, where $\mathrm{Cd}_{\alpha}$ and $\mathrm{Cd}_{\beta}$ denote the modifications of cadmium which are stable below and above $37.5^{\circ}$, respectively. 
(6) No experimental evidence has been obtained which would warrant the conclusion that more than two allotropes of cadmium exist between the freezing and boiling temperatures of water.

HILLSIDE LABORATORY, STAMFORD, CONA.

[Contribution from the Wolcott Gibbs Memorial Laboratory of Harvard University and the Chemical Laboratory of Vassar Colilege.]

\section{THE MELTING POINTS OF THE CHLORIDES OF LITHIUM, RUBIDIUM AND CAESIUM, AND THE FREEZING POINTS OF BINARY AND TERNARY MIXTURES OF THESE SALTS, INCLUDING ALSO POTASSIUM AND SODIUM CHLORIDE.}

By Theodore W. Richards and W. Buel, MEldoum. Received June 6, 1917.

The work recorded below was incidental to another research, for which it was desired to obtain eutectic mixtures of alkali chlorides. Since, however, the main research may not be soon completed, it is perhaps worth while to record the following incidental and incomplete resultsespecially since they confirm the recently published results of Korreng in points where his work differs from that of earlier investigators. ${ }^{1}$ The determinations recounted below were made during the winter of 19131914, before Korreng's work appeared.

\section{Preparation of Materials.}

Lithium Chloride.-For preliminary experiments a commercial sample, supposed to contain less than $0.1 \%$ of potassium and sodium, was employed; but it gave a melting point $12^{\circ}$ lower than the much purer specimen used in the final determinations. This latter substance was prepared from exceedingly pure lithium nitrate (remaining from the Harvard work on the atomic weight of lithium) ${ }^{2}$ by evaporating repeatedly with excess of hydrochloric acid in a quartz dish on an electric stove, finally fusing the salt in quartz in an atmosphere of hydrochloric acid gas.

Sodium Chloride.-A saturated solution of very pure sodium bicarbonate was neutralized with chemically pure hydrochloric acid. The solution was further saturated with hydrochloric acid and the salt precipitated. It was purified by reprecipitation.

Potassium Chloride.- "Chemically pure" potassium chloride from a competent firm was purified in a similar way by three precipitations with hydrochloric acid. Spectroscopic examination showed it to be free from sodium and other metals of the alkali group.

Rubidium Chloride.-Kahlbaum's salt, though free from other alkali metals, was found to contain rubidium nitrate in considerable quantity.

${ }^{1}$ Korreng, Z. anorg. Chem., 9I, 194 (I915); Chem. Abstracts, 9, 3040 (1915).

2 Richards and Willard, This Journal, 32, 4 (IgIO). 